\title{
A escola indígena como arma(dilha): reflexões a partir de uma pesquisa etnográfica entre os Guarani Mbya da capital paulista
}

\author{
Douglas Ladislau dos Santos*
}

\begin{abstract}
Resumo
Este artigo apresenta algumas reflexões em torno do termo "escola indígena". A investigação esforçou-se em identificar os aspectos considerados inovadores em uma experiência de escolarização de um coletivo indígena guarani. Procurar-se-á problematizar os modelos explicativos derivados das teorias consagradas ao contato interétnico, a partir de uma pesquisa etnográfica realizada entre os Guarani Mbya da capital paulista. Partindo de um campo de pesquisas que considera a escolarização de pessoas indígenas uma fronteira étnica, sugere-se aqui que a escola indígena é uma arma(dilha), um espaço de conflitos e redefinições, não necessariamente associada à construção identitária ou étnica.
\end{abstract}

Palavras-chave: Educação escolar indígena; Guarani Mbya; Teorias do contato interétnico.

\section{The indigenous school as a trap: reflections from an ethnographic research among the Guarani Mbya of São Paulo}

\begin{abstract}
This paper presents some reflections on the term "indigenous school". The research endeavored to identify the aspects considered innovative in a schooling experience of an indigenous Guarani collective. We will try to problematize the explanatory models derived from the theories dedicated to the interethnic contact, based on an ethnographic research carried out among the Guarani Mbya of São Paulo. Starting from a field of research that considers the schooling of indigenous people as an ethnic border, it is suggested here that the indigenous school is a trap, a space of conflicts and redefinitions, not necessarily associated to the identity or ethnic construction.
\end{abstract}

Keywords: Indigenous school education; Guarani Mbya; Theories of interethnic contact.

\section{Introdução}

Este artigo é fruto de uma pesquisa de mestrado que se iniciou em $2014^{1}$, contudo, não tinha o objetivo de investigar a complexa rede de relações que se delineia a partir da política pública da "educação escolar indígena específica, diferenciada, intercultural e bilíngue", cuja constituição foi analisada profundamente por Grupioni (2008). À época, almejava localizar, na cartografia escolar urbana, experiências de resistência e fugas ao padrão escolar dominante instituído.

As investigações de Abbonízio (2013) deslocaram meu ponto de vista, anteriormente centrado em experiências urbanas, às escolas denominadas indígenas. Aquela pesquisadora identificou um esforço local em associar objetivos escolares aos projetos de futuro da comunidade, processo interpretado como rompimento do paradigma colonialista em educação escolar indígena. Suas pesquisas basearam-se na experiência escolar dos Kotiria do município amazonense de São Gabriel da Cachoeira.

A partir deste primeiro contato com a temática da educação escolar indígena, a relação que os Guarani Mbya $^{2}$ estabelecem com a escola surgiu, graças a uma conversa com uma grande liderança guarani. Como pesquisador da Faculdade de Educação da Universidade de São Paulo, convidei os professores indígenas de uma escola guarani localizada na cidade de São Paulo para participarem de um projeto de extensão universitária, que consistia em realizar direitos humanos a partir da ação escolar.

No decorrer da conversa, a professora guarani demonstrou relativo interesse com a proposta, mas externou suas dúvidas em relação aos objetivos da instituição escolar. Segundo ela, a escola jurua ${ }^{3}$ é uma máquina que produz sujeitos padronizados. Ou, literalmente, "uma máquina de fazer salsicha". Já a escola indígena em que trabalha faz algo de diferente em relação às escolas dos brancos, apesar de ser também uma escola subordinada às diretrizes do sistema escolar estadual paulista. $\mathrm{Na}$ perspectiva da liderança guarani, sua escola é capaz de colaborar com o desenvolvimento das inúmeras potencialidades de seus estudantes.

Costumeiramente, os Mbya foram descritos como um povo que resistiu à escola. No entanto, atualmente, reivindicam a escola, mesmo sabendo que a instituição apresenta algumas características pouco desejáveis. Neste sentido, o 
que motiva os indígenas a desejarem escolas? $\mathrm{Ou}$ seria a escola um convite irrecusável? Tais perguntas nortearam a pesquisa, contudo, o que aqui se pretende apresentar é uma perspectiva teórica acerca da concepção de escola indígena. Tal perspectiva deriva de dois movimentos: uma pesquisa etnográfica realizada em uma aldeia guarani de São Paulo e um deslocamento conceitual da proposta de conceber a escola indígena como fronteira étnica.

A escola para índios (MELIÁ, 1979), fenômeno observado entre os Guarani Mbya da Serra do Mar (AZANHA; LADEIRA, 1989), têm como origem os processos de violência colonial por que passaram as populações indígenas situadas em um território que hoje abriga um Estado-nação chamado Brasil. A escolarização colaborou com a proposta assimilacionista e colonialista inerente à construção do país. Não obstante, após a intensificação dos movimentos organizados de resistência indígenas e indigenistas notada a partir dos anos 1970 (FERREIRA, 1992; GRUPIONI, 2008), o Estado brasileiro foi pressionado a produzir leis e direitos que garantissem, dentre outras demandas, uma educação escolar específica e diferenciada às populações indígenas.

Recentes pesquisas procuraram verificar até que ponto as conquistas legais e normativas impactam nas práticas escolares ameríndias (VALENTINI, 2010; BORSATTO, 2010). Algumas outras começaram a se preocupar com as apropriações desta escolarização dita diferenciada pelos diversos grupos indígenas, analisando experiências e tendo como princípio a ideia de que cada grupo indígena se relaciona com a escola de modo peculiar (BELTRAME, 2013; MARQUI, 2012; SANTIAGO, 2014).

No primeiro caso, embora as conquistas legais sejam notáveis, há pouca diferenciação e especificidade nos contextos escolares investigados. Já no segundo caso, observaram que cada grupo indígena se apropria e se relaciona com a escola disponível em seu território dos modos os mais variados, a ponto de alguns grupos se recusarem a aceitar uma escola de fato diferenciada, optando por uma versão escolar mais convencional.

Algumas experiências escolares indígenas apresentam características que se distinguem e rompem com o modelo escolar denominado colonialista, pois não usam mais exclusivamente a língua do colonizador, a religião do colonizador e, o mais importante, as mudanças trazidas pela escola são controladas e escolhidas pelos indígenas, de um modo a conciliar os objetivos escolares com os projetos de futuro das comunidades (ABBONÍZIO, 2013). Segundo
Abbonízio, experiências escolares indígenas que procuram se afastar, de algum modo, de práticas escolares com características colonialistas são exemplos de inovação educacional.

As ambiguidades e contradições inerentes à escola indígena serão compreendidas à luz do conceito de arma (dilha), que surgiu a partir de dois movimentos: uma pesquisa etnográfica realizada em uma aldeia guarani e um deslocamento conceitual derivado de estudos que consideram a escola indígena uma fronteira étnica. Para realizar esse objetivo, a próxima seção do artigo apresenta a construção do objeto de pesquisa e os interlocutores com quem o pesquisador relacionouse. A seguir, pretende-se problematizar a definição de escola indígena. As três seções posteriores dedicam-se à problematização da ideia de escola indígena como fronteira étnica. Como conclusão, apresenta-se uma reflexão em torno dos perigos da escola entre os Guarani Mbya da capital paulista.

\section{O caso guarani}

Conforme o Censo de 2010, a população paulistana alcançou a marca de 11 milhões de habitantes. Deste total, cerca de 13 mil pessoas se autodeclararam indígenas $(0,12 \%$ da população total do município). Das que se declararam indígenas, umas poucas vivem em algum território denominado indígena neste município. Quando o universo é o país, o Censo confirmou uma população indígena de 817.963 pessoas.

Na capital paulista, estima-se que há 1.357 pessoas vivendo em territórios indígenas, nos arredores do Parque Estadual do Jaraguá e no extremo sul da cidade, nos limites do Parque Estadual da Serra do Mar. Boa parte desta população é constituída por crianças e jovens, ou seja, potenciais sujeitos ${ }^{4}$ da escolarização. Há três escolas estaduais em territórios indígenas na cidade de São Paulo ${ }^{5}$. Essas instituições se ocupam do ensino fundamental e médio. Há também três escolas municipais indígenas ${ }^{6}$, que se responsabilizam pela educação escolar indígena infantil.

$\mathrm{O}$ foco das atenções desta pesquisa foi a Escola Estadual Indígena Guarani (EEIG) Gwyra Pepo, localizada na aldeia Tenonde Porã, que fíca no distrito de Parelheiros, extremo sul do município paulistano. Trata-se da aldeia indígena mais populosa do estado de São Paulo, com um total estimado de 800 a 1000 pessoas.

Para verificar as especificidades da experiência escolar mbya, a pesquisa sustentou que há princípios gerais que configuram o denominado "padrão escolar dominante". Os princípios orientam as práticas escolares, indígenas e não 
indígenas, instituindo modos considerados adequados de agir e pensar. Esses princípios são as matrizes da armadura da gramática escolar (GOMES; MIRANDA, 2014).

Dentre os princípios, especulou-se que alguns se expressam com maior intensidade entre os Mbya da aldeia Tenonde Porã: a escola é estatal ${ }^{7}$, não apresenta uma preocupação imediata com as condições atuais de vida das pessoas atingidas por sua ação, procura negar outros modos de produção e circulação de conhecimentos ${ }^{8}$, é baseada em práticas escritas $^{9}$ e recintuais ${ }^{10}$.

As descobertas etnográficas indicam a continuidade, apesar de resistências locais, dos princípios do denominado "padrão dominante escolar". O que interessa ao artigo são os impactos destas descobertas no campo acadêmico que procura compreender a educação escolar indígena. A seguir, algumas explicitações dessas descobertas.

\section{O que são escolas indígenas?}

Escolas indígenas são escolas ou projetos de escolarização baseados em territórios indígenas, não necessariamente em Terras Indígenas demarcadas (TIs). Isto é, em terras tradicionalmente ocupadas pelos indígenas, conforme o disposto no artigo 231 na Constituição de 1988, terras "por eles habitadas em caráter permanente, as utilizadas para suas atividades produtivas, as imprescindíveis à preservação dos recursos ambientais necessários a seu bem-estar e as necessárias à sua reprodução física e cultural, segundo seus usos, costumes e tradições" (BRASIL, 1988). A EEIG Gwyra Pepo é uma escola indígena, seguindo a definição acima, pois está instalada na aldeia guarani Tenonde Porã, atualmente situada na TI Tenonde Porã ${ }^{11}$.

A escola indígena, em maior ou menor intensidade conforme casos específicos, também opera segundo os princípios do chamado padrão escolar dominante: é um aparelho de dominação (estatal), baseada em práticas escritas e recintuais, procura negar outros modos de produção e circulação de saberes e não apresenta uma preocupação imediata com as condições atuais de vida das pessoas atingidas por sua ação.

Especificamente, se comparada às escolas não indígenas, a escola indígena vem sendo manejada pelos coletivos indígenas como um instrumento conceituado de luta e se apresenta como um locus produtivo de enunciados culturais. Os indígenas procuram se apropriar do pacote escolar que lhes é oferecido, com o objetivo de melhor controlar as relações que estabelecem (ou às quais são submetidos) com a sociedade envolvente, de modo a inventar a desejada autonomia, que foi sistematicamente negada e destruída a partir das grandes invasões europeias.

Quanto aos Guarani da capital paulista (e, especulativamente, aos demais coletivos indígenas), há uma novidade. Por conhecerem os riscos inerentes ao pacote escolar, pode-se conceber a escola indígena como arma(dilha). Domesticar a escola ou pelo menos minimizar seus possíveis efeitos danosos, um desafio cotidiano encarado pelos interlocutores da pesquisa. Antes de esclarecer tal perspectiva, os modelos teóricos preponderantes neste campo científico serão explicitados.

\section{Modelos teóricos preponderantes}

As pesquisas de Tsupal (1978) e Assis (1981) inauguram o campo em torno da chamada "educação escolar indígena". Já os anos 1990 marcaram um aumento exponencial na temática. Além do crescimento significativo, uma tendência explicativa se constituiu. A maior parte dos pesquisadores que se atreveu a investir no tema costuma partir de alguma teoria do contato interétnico. A classificação apresentada a seguir é inspirada em Tassinari (2001).

Há três modelos argumentativos preponderantes. O primeiro descende dos teóricos da aculturação, que observam a decadência e destruição das instituições sociais aborígenes ao se relacionarem com o mundo ocidental. Tal argumento é denominado "escola indígena destruidora". No caso das escolas indígenas, o fato de existirem já denota algum tipo de perversão do modelo cultural tradicional. Estes autores postulam a existência de um sistema cultural único, que incorpora ou elimina as ditas culturas tradicionais. Neste modelo, a escola implantada em territórios indígenas é um espaço ocidental por excelência. A escola é colonizadora, civilizadora, unificadora e homogeneizadora. Surge para garantir os ideais do projeto colonizador europeu e, posteriormente, pretende garantir a integração nacional do Estado brasileiro. Esta escola ameaça a sobrevivência indígena, pois substitui os modos tradicionais de educação pelo modelo escolar, baseado na língua portuguesa escrita e no conhecimento disciplinar. Para Tassinari, este período ficou para trás.

Pode-se definir o segundo modelo argumentativo como "escola ressignificada". Esta abordagem ancora-se em Sahlins (1997). Contrariamente à postura anterior, o contato entre a cultura ocidental e a cultura indígena não é, a princípio, possuidor de um mal de raiz. O contato produz novos modelos culturais. Deste modo, a escola quando implantada em territórios indígenas, por mais que tenha uma origem ocidental, será 
ressignificada conforme as categorias nativas. De certo modo, a escola se transforma em uma instituição indígena.

$\mathrm{O}$ terceiro modelo argumentativo é a "escola fronteiriça". O foco das atenções são os espaços de intercâmbio, a resistência se dá na manutenção e emergência das diferenças nos espaços de contato. Barth (1969) está na gênese deste modelo. A escola indígena é entendida como um espaço de contato, na qual emergem as diferenças entre dois grupos étnicos: os ocidentais e os indígenas. As diferenças emergem e adquirem um novo significado, as tradições e técnicas destes dois mundos são postas em contato, são trocadas e reinventadas. A escola é fronteira étnica.

As transformações culturais também podem ser compreendidas a partir de outras perspectivas. Porém, a maior parte das pesquisas elege a escola como um território que potencializa o encontro de culturas solidamente separadas, seja destruindo a mais fraca (escola destruidora), seja transformando a instituição escolar ocidental por força centrípeta (escola ressignificada), ou, mais comumente, concebendo a escola como um território mediador (escola fronteiriça).

\section{O discurso estabilizado sobre a educação escolar indígena}

Por mais que haja uma multiplicidade de autores com tendências teóricas variadas e que optaram por diversos caminhos de pesquisa, há talvez uma inclinação observável em muitas das pesquisas em torno da educação escolar indígena. Um conjunto heterogêneo de pesquisadores, artigos, teses, dissertações e livros sobre educação escolar indígena, publicados a partir de $1992^{12}$, vem desenvolvendo um discurso científico dotado de certa homogeneidade.

Em suma, entende-se que a educação escolar indígena, após a emergência de movimentos indígenas organizados $\mathrm{e} d \mathrm{da}$ promulgação da Carta Magna de 1988, ao mobilizar os coletivos indígenas na realização de sua educação escolar, estabeleceu (potencialmente) uma escola diferenciada, intercultural e bilíngue; antes, a escola servia para a aculturação dos povos ameríndios; atualmente (a partir de 1988), a escola indígena é um elemento conceituado de luta para garantir seus modos de vida. Esse discurso é base de parte considerável das pesquisas em educação escolar indígena dos últimos vinte anos. A seguir, evidencia-se esse discurso em alguns trabalhos. $\mathrm{O}$ objetivo, em suma, é demonstrar que a escola indígena vem sendo concebida como um instrumento conceituado de luta.

Entre Ferreira (1992) e Delmondez e
Pulino (2014), respectivamente, a primeira e a última obra examinadas, pouco mais de 20 anos se passaram, diversas experiências práticas se concretizaram, muitas novidades na legislação educacional indígena surgiram. $\mathrm{O}$ mais evidente neste cenário é a estabilização teórica, política e prática do enunciado que define a nova escola indígena como diferenciada, intercultural, bilíngue e voltada aos interesses dos coletivos indígenas.

A compreensão de que a escola indígena é um instrumento conceituado de luta, conclusão de Ferreira, surge nos movimentos indígenas e indigenistas dos anos 1970 e 1980, concretiza-se na Carta Magna de 1988 e se transforma em enunciado científico no decorrer das décadas de 1990 e 2000. Hoje, este discurso é usual entre professores indígenas, pesquisadores, autoridades políticas e funcionários das secretarias de educação que atuam nos núcleos de educação escolar indígena. Não é possível afirmar que este discurso é consensual, mas, ao que tudo indica, é forte e direciona grande parte das pesquisas e práticas nesta área.

Ferreira $(1992,2001)$ passa a ser referência quando o assunto é educação escolar indígena, sobretudo o seu modelo de classificação histórica, que divide a escolarização dos povos indígenas no Brasil em quatro períodos, que por vezes se intercalam, mas que denotam uma tendência, "a finalidade do Estado brasileiro, que procura aculturar e integrar os índios à sociedade envolvente por meio da escolarização, confrontase, atualmente, com os ideais de autodeterminação dos povos" (FERREIRA, 2001, p. 71).

Desde então, o campo de estudos voltados à educação escolar indígena, direta ou indiretamente, sofre influências desta constatação, "os índios recorrem à educação escolar, hoje em dia, como instrumento conceituado de luta" (FERREIRA, 2001, p. 71). Quanto ao modelo explicativo, Ferreira apropria-se do argumento da escola ressignificada, inspirada nos trabalhos de Sahlins.

O argumento principal de Abbonízio (2013) segue uma direção semelhante, pois no contexto de sua pesquisa, os Kotiria se apropriam e ressignificam a escola, de modo a compatibilizar a educação escolar com seus projetos de futuro. $\mathrm{Na}$ concepção desta autora, a educação escolar indígena praticada entre os Kotiria é um exemplo de inovação educacional, pois superou o caráter costumeiramente colonialista da escola para índios, já que sua implantação e manutenção pretende abarcar os projetos de futuro da comunidade, algo raramente notado até este momento, no que concerne à educação escolar brasileira.

Uma obra cronologicamente próxima à de 
Ferreira (1992), Ferreira Neto (1994), apresenta os resultados de sua pesquisa sobre alfabetização entre os Guarani da aldeia Ribeirão Silveira. Segue o modelo histórico proposto por Ferreira (1992) e adere ao terceiro modelo argumentativo de contato (escola fronteiriça), ao alinhar as conclusões de sua pesquisa à teoria das fronteiras étnicas de Barth (1969). A escola indígena é colocada em uma perspectiva muito próxima ao discurso estabilizado, ela é "um instrumento capaz de fornecer-lhes as técnicas necessárias para o trato com a sociedade nacional brasileira" (FERREIRA NETO, 1994, p. 105). A escolarização não é entendida como um elemento demandado pelas populações indígenas, contudo, é concebida também como um instrumento de luta, que faz parte dos desejos manifestados pelos coletivos indígenas, a qual fornecerá as técnicas e instrumentos necessários para o relacionamento com a sociedade nacional.

Apropriando-se da distinção já consagrada entre educação indígena e educação para índios, estabelecida por Melià (1979) e ampliada por Silva (1981), Kahn (1994) afirma a impossibilidade de conceber uma educação escolar indígena de fato, pois, por mais que se pretenda diferenciada, a escola é uma instituição social ocidental, dirigida e pensada por brancos. Até em casos onde há gestores e professores oriundos de populações indígenas, o treinamento e a formação destes profissionais obedeceu a uma lógica ocidental. Aparentemente, Kahn esboça seguir outra tradição explicativa (escola indígena destruidora), antípoda ao modelo estabilizado defendido neste texto. Porém, ela conclui sua linha argumentativa convocando as comunidades indígenas a tomarem as rédeas de sua educação escolar, deste modo, as instituições escolares serviriam aos objetivos coletivos dos indígenas. Portanto, orienta-se no sentido (de modo normativo) do enunciado estabilizado. A escola para índios só deixará de apresentar as características coloniais e catequizantes quando for controlada coletivamente pelos indígenas.

Com um salto de cinco anos, Borges (1999) reforça a tese do enunciado estabilizado, ao apresentar a forma com que os Guarani Mbya da aldeia Sapucay (Angra dos Reis, RJ) lidam com os conhecimentos históricos. Segundo esse autor, a escola indígena implantada na região adquiriu a conotação de uma "educação escolar intercultural", pois se utiliza de documentações imagéticas produzidas por não índios como fontes históricas na reconstrução das memórias históricas dos indígenas. Adotou parcialmente o modelo argumentativo da escola fronteiriça e, como seus pares, constrói sua pesquisa adotando o pressuposto do enunciado estabilizado. No caso estudado, a escola é utilizada pelos coletivos indígenas para reconstruírem suas memórias históricas.

\section{Os impactos da etnografia no discurso estabilizado}

A proposta teórico-metodológica aqui apresentada, que tem o objetivo explícito de produzir diferenças nos modos discursivos acerca da educação escolar indígena, apoia-se em experiências etnográficas. Ou seja, foi na tentativa de traduzir a perspectiva dos professores guarani da capital que uma nova possibilidade teóricometodológica se constituiu. A partir dessas experiências, percebeu-se que a escola indígena disponível tem um potencial de se transformar em um instrumento conceituado de luta, pois, por seu intermédio, domina-se a letra jurua, indispensável às lideranças que procuram garantir os direitos territoriais, por exemplo. Contudo, eleger a escola como mecanismo de luta é submeter-se a riscos, a gramática da escola está mais para armadura e se apresenta aos Guarani como arma(dilha).

$$
\text { Como sugeriu Grupioni (2008), }
$$
multiplicaram os contextos em que as lideranças indígenas são instadas a produzirem discursos sobre suas culturas, sendo a escola um locus produtivo de enunciados culturais. Entre os Mbya da Tenonde Porã, situação semelhante foi verificada no decorrer do trabalho de campo. Para elucidar, uma das interlocutoras da pesquisa, além de professora da EEIG Gwyra Pepo, é uma das lideranças guarani mais ilustres em cenários jurua de enunciação cultural, como as universidades. Ao se descrever, ela se vê como uma "agente cultural". Ela e outros professores da Tenonde Porã são constantemente convidados a elaborarem discursos sobre a "cultura" guarani. Muitas vezes, a "cultura" é manejada como estratégia de "trazer recursos à comunidade".

A seguir, esclarece-se o entendimento acerca da noção de arma(dilha). A ideia de escola enquanto risco se constitui, empiricamente, a partir da tomada de alguns princípios. O primeiro é a escrita. O clássico Melià (1979) ainda tem muito a ensinar. É um livro fundante e fundamental aos que desejam saber mais sobre o impacto da escola e da alfabetização nos processos próprios de aprendizagem dos grupos indígenas. Por ter sido publicado em 1979, ou seja, contemporâneo à pesquisa de Tsupal (1978), pode ser considerado um livro que funda um campo de saber, hoje já bastante rico em publicações.

Educação pode dar-se muito bem sem 
alfabetização. Alfabetização, no entanto, nem sempre assegurará uma boa educação. As sociedades indígenas brasileiras, como, aliás, muitas outras sociedades em todo o mundo, se educaram perfeitamente durante séculos sem recorrer à alfabetização, conseguindo, com meios quase que exclusivamente orais, criar e transmitir uma rica herança cultural. A educação baseada na comunicação oral até apresenta não poucas vantagens sobre a baseada na escrita. Nas culturas orais nota-se uma participação mais homogeneizada e plena de todos no saber tradicional, uma grande riqueza de sabedoria proverbial, uma visão mais unitária do mundo, uma forte vivência do presente como tal, uma captação da vida como um todo e não simplesmente acumulação de coisas separadas. A alfabetização, de fato, incentiva a privatização do saber e contribui para um tipo de individualização que logo se manifesta fonte de tensões e conflitos sociais entre dominante e dominado. (MELIÀ, 1979, p. 7)

Melià concebe a educação como um processo social total, "socialização integrante" (MELIÀ, 1979, p. 10), uma atuação integrante da cultura sobre os membros da comunidade. Para ele, "a educação de cada índio é interesse da comunidade toda" (MELIÀ, 1979, p. 10). Sendo educação sinônimo de socialização, a educação praticada nas escolas é um tipo de socialização, baseada na escrita, gerada no seio dos Estados nacionais e que, pelos processos de violência colonial, transformou-se também em uma necessidade dos povos indígenas. Aqui reside a distinção clássica entre educação indígena $\mathrm{e}$ educação para o indígena.

A educação para o indígena é aquela produzida no decorrer da ocupação europeia, por meio dos jesuítas e outras parcelas missionárias. Com a construção do Estado-nação Brasil, a educação para o indígena passou a ser sua preocupação. Hoje, com as conquistas legais concretizadas na $\mathrm{CF} / 1988$, as escolas alternativas mantidas pelas comunidades indígenas e por ONGs indigenistas vêm sendo substituídas por escolas mantidas pelo poder estatal. Contudo, o cerne da escola permanece, como diria Melià, na substituição de uma educação baseada na oralidade por uma educação centrada na escrita.

Na concepção de Melià, a escrita e a escola produzem efeitos nas sociedades ágrafas. Primeiramente, ela incentiva a privatização do saber, já que, com a introdução da escrita, os conhecimentos são circulados privativamente, diferentemente dos modos coletivos tipicamente orais. No caso mbya, nota-se um afastamento dos jovens letrados dos espaços de produção e circulação de conhecimentos coletivos, como as casas de reza. Os jovens são apontados como "distraídos e com pouca capacidade de concentração, não sabem se concentrar na opy", apontou uma liderança guarani da Tenonde Porã, insatisfeita com os impactos da escola nas novas gerações.

A individualização produzida pela introdução da escrita vira fonte de tensões, consideradas por Melià como "conflitos entre dominantes e dominados". Divide-se o coletivo entre pessoas letradas e iletradas, os letrados exercem poder sobre os iletrados. Alguns eventos registrados no diário de campo desvelam a tensão sugerida por Melià.

Uma professora relatou um caso de quando vivia em outra aldeia. Alguns jovens da aldeia invadiram sua casa e roubaram alimentos e outros pertences de baixo valor econômico. $\mathrm{O}$ interesse desse caso reside nos motivos expostos, pois, segundo a professora, a existência da escola produziu algumas desigualdades na aldeia. $\mathrm{O}$ domínio da escrita por algumas pessoas da aldeia levou ao assalariamento, fonte de tensões e conflitos.

Um segundo exemplo elucidará melhor a questão. Para terem acesso aos programas de transferência de renda, as famílias devem cumprir uma série de requisitos, tendo como princípio comum entre as diversas políticas a exigência de frequência escolar, isto é, somente famílias com pessoas letradas ou em processo de alfabetização ou escolarização têm acesso aos programas.

A partir de Melià, pode-se identificar a primeira característica da escola indígena: ela é uma das responsáveis pela introdução da escrita nos mundos indígenas, processo denominado por Certeau (2002) de modernização da cultura e sua introdução carrega em si um novo modo de exercício de poder (LÉVI-STRAUSS, 2014), aspectos evidenciados em diversas ocasiões ao longo do trabalho de campo.

O segundo princípio da escola indígena é apresentar aos Guarani as práticas recintuais. Recinto "é tudo aquilo cuja função é fechar, tal uma caixa, assim criando simultaneamente, no mesmo ato, um dentro e um fora. É aquilo então que serve para separar e conhecer agentes em situações controladas" (MARRAS, 2006, p. 358). A escola costuma ser um espaço específico, delimitado e isolado das outras atividades sociais. A escola faz isso em um prédio que cria simultaneamente um dentro e um fora, fechando os agentes que se quer conhecer e separar em uma situação controlada: os estudantes, mas não só eles, pois os professores e demais agentes também sentem os efeitos recintuais. 
O terceiro princípio é a heteronomia política da escola indígena. A escola Gwyra Pepo é mantida pelo governo estadual de São Paulo, assumindo desde já feições estatais: ela foi criada por uma lei, é gerida por princípios da administração pública, com notáveis características hierárquicas e de concentração de poder. Pode-se dizer que o monopólio do uso legítimo da força ocorre na escola.

Todavia, a escola entendida como um aparelho de dominação refere-se especialmente a processos denominados micropolíticos, que incidem nos corpos dos agentes submetidos à sua ação: observam-se pequenos mandos nos "comunicados escolares", o controle dos corpos que são separados em classes ou turmas, a vigilância constante dos professores por meio dos "diários de classe" e "livros-ponto".

Outros dois princípios caracterizam o padrão escolar dominante e se apresentam aos Mbya da Tenonde Porã com níveis variados de intensidade. Um dos princípios considera que a legitimidade dos saberes escolares decorre de um processo que procura universalizar os conhecimentos e práticas de determinados grupos sociais, impondo-os aos demais grupos. $\mathrm{O}$ outro princípio afirma que a escola e seus diversos agentes não atuam para se ocupar imediatamente com as condições atuais de vida das pessoas atingidas por sua ação. A ação escolar está voltada para o futuro, um porvir geralmente inalcançável pelos sujeitos da pesquisa: vestibular, inserção no mercado de trabalho urbano, conquista de uma cidadania baseada na cultura política ocidental.

\section{Conclusão}

Os estudos sobre a escolarização de pessoas indígenas inspiram-se, sobretudo, em abordagens antropológicas ancoradas nos teóricos do contato interétnico. Desde o início dos anos 1990, uma dessas perspectivas ganha força e se estabelece quase como um paradigma: a escola indígena é uma fronteira étnica. Não foi o objetivo do artigo refutar essa perspectiva, mas sim apresentar outro modo de pensar os problemas da escola indígena. Ao problematizar a ideia de escola como fronteira a partir de um estudo etnográfico, argumenta-se que, entre os Mbya da capital paulista, a escola é vista como um elemento ambíguo e conflituoso que não produz, necessariamente, identidades a partir do contato entre mundos distintos: o da escola ocidental e o guarani.

Uma Karipuna, ao ser indagada por Tassinari (2001), respondeu que não se lembrava "de quando os macacos eram gente". Esta mulher karipuna havia conhecido o mito com uma professora não indígena: a teoria da evolução das espécies de Darwin. Na concepção karipuna, macacos e outros bichos são gente, isto é, vivem em aldeias e fazem festas em uma vida paralela à nossa. São gente, pois produzem relações sociais.

Um mito evidentemente perspectivista. A explicação evolucionista talvez fosse uma versão mais recente de algum mito karipuna, quem sabe até uma transformação estrutural do mito. Segundo Tassinari, este é um exemplo interessante de articulação entre dois sistemas de conhecimento (indígena e ocidental), de modo a produzir uma nova explicação. A escola "[...] é como uma porta aberta para outras tradições de conhecimentos, por onde entram novidades que são usadas e compreendidas de formas variadas" (TASSINARI, 2001, p. 50).

O artigo apresenta uma objeção a proposta de Tassinari: a ideia de conceber "a escola indígena enquanto espaço de interação e contato entre populações, onde há fluxos de pessoal e conhecimento e onde as diferenças sociais são construídas" (Idem, p. 65). Até é possível entender a escola como espaço, porém a política escolar não é algo constituído somente por um espaço, ela é um híbrido (agentes humanos e não humanos, conhecimentos, políticas e práticas). Ela é um espaço de interação, mas, não é só isto, é um objeto de luta, um híbrido que gera conflitos. Há contato entre populações, mas, as relações e efeitos extrapolam o termo população. Há fluxo de pessoas e conhecimentos, contudo, o pacote escolar é um sistema de conhecimentos pouco suscetível a variações internas. Não é a escola que produz diferenças, ela tenciona mais à homogeneidade $\mathrm{e}$ busca combater a produção de diferenças. Por saberem disso, os professores mbya com quem convivi estabelecem uma relação de desconfiança com a escola, sobretudo quando almejam lidar com saberes que não devem ser escolarizados.

Conforme exposto ao longo do artigo, pretende-se apresentar uma nova perspectiva teórico-metodológica acerca do problema da educação escolar indígena. Diferentemente das propostas preponderantes, evidentemente baseadas nos teóricos do contato interétnico, efetuou-se aqui um deslocamento conceitual baseado em experiências etnográficas. Sugere-se, a partir das traduções e das hibridizações da Escola Guarani Gwyra Pepo, que a escola indígena se apresenta como arma(dilha). A escola indígena é um risco. $\mathrm{O}$ modo de agir da escola potencialmente produz transformações nos coletivos indígenas. "Escolher" a escola como um instrumento conceituado de luta é dispor-se a encarar seus perigos. A reflexão proposta a seguir procura 
explorar os riscos inerentes à escola.

$\mathrm{O}$ primeiro aspecto identificado no decorrer da pesquisa refere-se à característica da escola em agir como marcador social de tempo. Dia letivo, horário de aula, férias, finais de semana, feriados, hora do recreio, hora de comer, em suma, práticas escolares que geram efeitos no modo guarani de organizar o tempo. Marqui (2012) notou semelhante efeito entre os Mbya de Nova Jacundá.

Para controlar o poder da escola de "mudar o tempo", os professores pretendem alterar o calendário oficial da Escola Gwyra Pepo. A mudança do tempo da escola ocorrerá com a construção do Projeto Político Pedagógico (PPP) da escola, processo em andamento e que conta com a participação de professores, estudantes, lideranças, anciãos, Funai e autoridades universitárias.

A maior parte das pesquisas concebe a educação escolar indígena como instrumento político. A escola é apropriada pelos grupos indígenas. A educação escolar destinada aos indígenas se configura em uma ferramenta que colabora na construção da autonomia destes povos. $\mathrm{O}$ foco da escola indígena é voltar-se para as relações com o Estado.

Testa (2007) apresenta outra perspectiva, já que a escola é "um espaço que é também permeado pelas formas de organização política da própria aldeia. Neste sentido, sem o apoio e confiança das demais lideranças, os professores correm o risco de serem sempre alvo de questionamentos e críticas e serem substituídos ou verem todos seus matriculados em escolas fora das aldeias" (TESTA, 2007, p. 67). A autora refere-se às aldeias da TI Jaraguá, cujo elemento político que evita o acirramento das disputas é o xeramoi Kamba, que "acaba frequentemente tentando conciliar as posições divergentes que diferentes lideranças apresentavam para evitar conflitos maiores" (Idem, p. 67). Na Tenonde Porã, no que diz respeito à escola, a figura que evita o feud é a professora mencionada no início do artigo. Uma concepção agonística da escola guarani, raramente verificada nas pesquisas disponíveis.

\section{Notas}

$1 \mathrm{O}$ artigo deriva de problemas surgidos durante a escrita da dissertação de mestrado defendida em 2017. Contei com uma bolsa de estudos do CNPq. Sou eternamente grato aos professores mbya da aldeia Tenonde Porã, com os quais pude aprender um pouco da arte de resistir e existir.

2 Segundo o Instituto Socioambiental (2017), há três parcialidades guarani no Brasil: Ñandeva, Kaiowa e Mbya. No mestrado, realizei trabalhos de campo em aldeias guarani mbya da capital paulista. Os principais interlocutores desta pesquisa foram os professores indígenas que atuam na escola estadual da aldeia Tenonde Porã, localizada na região sul da cidade.

3 Palavra guarani utilizada para se referir aos não indígenas.

4 São sujeitos da escolarização, pois são pessoas potencialmente submetidas à ação escolar. Outro sentido possível seria o de afirmar que os sujeitos da escolarização são atores de sua escolarização. A escolarização comumente nega o imperativo da agência para as pessoas que são alvo de sua ação, com uma tendência forte a monopolizar a educação e de impossibilitar outras formas de aprendizado (CARNEIRO DA CUNHA, 2014).

5 Borsatto (2010) realizou pesquisas nas duas escolas indígenas da zona sul de São Paulo. A autora focou especificamente a construção curricular da escola situada na aldeia Krukutu. Em uma perspectiva semelhante, Valentini (2010) pretendia verificar se as práticas escolares observadas na escola indígena localizada no Jaraguá efetivavam uma educação de fato diferenciada, tal como dispõe a legislação educacional brasileira.

6 Trata-se do Centro de Educação e Cultura Indígena (Ceci). Ferreira (2012) narra a implantação deste equipamento cultural na aldeia Krukutu, concluindo que todos os habitantes daquele território atribuem um grande valor à educação escolar indígena infantil. Em cada Ceci, funciona um CEII (Centro de educação Infantil Indígena).

7 É a forma de governar da escola, o modo como a instituição procura submeter os agentes sob sua jurisdição.

$8 \mathrm{~A} \mathrm{CF} / 1988$, em seu art. 206, inciso II, estabelece como um dos princípios educacionais brasileiros a "liberdade de aprender, ensinar, pesquisar e divulgar o pensamento, a arte e o saber". A Carta Magna garante, no $2^{\circ}$ parágrafo do art. 210 , que "o ensino fundamental regular será ministrado em língua portuguesa, assegurada às comunidades indígenas também a utilização de suas línguas maternas e processos próprios de aprendizagem". Conforme os dois princípios constitucionais, os processos próprios de aprendizagem dos diversos grupos indígenas devem ser respeitados pelo sistema escolar. $\mathrm{O}$ sistema educacional brasileiro admite como princípio a liberdade de aprender, ensinar, pesquisar e divulgar em todos os seus âmbitos e níveis, independentemente do grupo étnico ou estilos de vida: a escola, conforme preceito constitucional, não pode produzir elementos coercitivos que limitem ou neguem os mais 
variados modos de circulação e produção de conhecimentos. Contudo, um dos pressupostos desta pesquisa é que o sistema escolar e muitos de seus atores não procuram respeitar os princípios constitucionais citados, pois legitimam certos saberes e modos de aprender e negam outras possibilidades. O artigo de Santos (2018) retoma e aprofunda essa questão.

9 A escrita será tomada, de início, como uma tecnologia apropriada ao desenvolvimento dos Estados nacionais e, por este motivo, entendida como exercício de poder.

10 Marras (2006) afirma que recinto "é tudo aquilo cuja função é fechar, tal uma caixa, assim criando simultaneamente, no mesmo ato, um dentro e um fora. É aquilo então que serve para separar e conhecer agentes em situações controladas de misturas e purificações sucessivas.” (p. 358). É uma prática, como diz aquele pesquisador, "tão cotidiana e familiar que, talvez por isso mesmo, não nos damos conta de seu valor, por assim dizer, cosmológico." (MARRAS, 2006, p. 359). Marras sugere que as práticas recintuais não são exclusivas de coisas e objetos, ocorrem também em compostos estabilizados como sociais, citando o caso das escolas e presídios. Aspectos denominados "práticas recintuais", como a separação dos estudantes conforme as faixas etárias, expressam-se de modo intenso na EEIG Gwyra Pepo.

11 A demarcação da TI Tenonde Porã foi garantida com o Ato Declaratório do ministro da Justiça (MJ), conforme Portaria Declaratória do MJ de $\mathrm{n}^{\circ}$ 548, publicada no Diário Oficial da União (DOU) em 6 de maio de 2016.

12 Data da publicação da dissertação de mestrado de Mariana Kawall Leal Ferreira, que talvez tenha inaugurado este campo.

\section{Referências}

ABBONÍZIO, Aline Cristina de Oliveira. Educação escolar indígena como inovação educacional: a escola e as aspirações de futuro das comunidades. 2013. 193 p. Tese (Doutorado em Educação) - Faculdade de Educação, Universidade de São Paulo, São Paulo, 2013.

ASSIS, Eneida Corrêa de. Escola indígena, uma "frente ideológica"? 1981. 204 p. Dissertação (Mestrado em Educação) - Universidade de Brasília, Brasília, 1981.

AZANHA, Gilberto; LADEIRA, Maria Inês. Os indios da Serra do Mar: a presença Mbya -
Guarani em São Paulo.1. ed. São Paulo: Nova Stella, 1988.

BARTH, Fredrik (org.). Ethnic groups and boundaries: the social organization of culture difference. 1. ed. London: Universitets Forlaget; Oslo: George Allen \& Unwin, 1969.

BELTRAME, Camila Boldrin. Etnografia de uma escola Xikrin. 2013. 166 p. Dissertação (Mestrado em Antropologia Social) - Universidade Federal de São Carlos, São Carlos, 2013.

BORGES, Paulo Humberto Porto. Uma visão indígena da história. Cadernos Cedes, ano XIX, $\mathrm{n}$. 49, p. 92-106, 1999.

BORSATTO, Fernanda Serra. Educação escolar indígena: construção curricular da Escola Estadual Indígena Krukutu. 2010. 127 p. Dissertação (Mestrado em Educação) - Pontifícia Universidade Católica, São Paulo. 2010.

BRASIL. Constituição Federal de 1988. Promulgada em 5 de outubro de 1988. Disponível em:

$<$ http://www.planalto.gov.br/ccivil_03/constituica o/constituição.htm> Acesso em: $1 \overline{6}$ dez.2016.

CARNEIRO DA CUNHA, Manuela. Políticas culturais e povos indígenas: uma introdução. In: CARNEIRO DA CUNHA, Manuela; CESARINO, Pedro de Niemeyer (Orgs.). Políticas culturais e povos indígenas. São Paulo: Unesp, 2014. p. 9-21.

CERTEAU, Michel de. A invenção do cotidiano: artes de fazer. Tradução de Ephraim Ferreira Alves. 7. ed. Petrópolis: Vozes, 2002.

DELMONDEZ, Polianne; PULINO, Lucia Helena Cavasin Zabotto. Sobre identidade e diferença no contexto da educação escolar indígena. Psicol. Soc.; v. 26, n. 3, p. 632-641; 2014.

FERREIRA, Edna. A criação do Centro de Educação e Cultura Indígena (CECI) e a educação infantil indígena na aldeia Krukutu. São Paulo. 2012. 112 p. Dissertação (Mestrado em Educação) - Pontifícia Universidade Católica, São Paulo. 2012.

FERREIRA, Mariana Kawall Leal. Da origem dos homens à conquista da escrita: um estudo sobre povos indígenas e educação escolar no Brasil. 1992. 225 p. Dissertação (Mestrado em Antropologia Social) - Faculdade de Filosofia, 
Letras e Ciências Humanas, Universidade de São Paulo, São Paulo, 1992.

. A educação escolar indígena: um diagnóstico crítico da situação no Brasil. In: FERREIRA, Mariana Kawall Leal; SILVA, Aracy Lopes da. Antropologia, história e educação: a questão indígena e a escola. São Paulo: Fapesp, 2001, p. 71-111.

FERREIRA NETO, Waldemar. Índios e a alfabetização: aspectos da educação escolar entre os Guarani de Ribeirão Silveira. 1994. 112 p.

Dissertação (Mestrado em Linguística) Faculdade de Filosofia, Letras e Ciências Humanas, Universidade de São Paulo, São Paulo, 1994.

GOMES, Ana Maria R.; MIRANDA, Shirley Aparecida de. A formação de professores indígenas na UFMG e os dilemas das 'culturas' entre os Xakriabá e os Pataxó. In: CARNEIRO DA CUNHA, Manuela; CESARINO, Pedro de Niemeyer (Orgs.). Políticas culturais e povos indigenas. São Paulo: Unesp, 2014, p. 455-484.

GRUPIONI, Luís Donisete Benzi. Olhar longe, porque o futuro é longe: cultura, escola e professores indígenas no Brasil. 2008. 240 p. Tese (Doutorado em Antropologia Social) - Faculdade de Filosofia, Letras e Ciências Humanas, Universidade de São Paulo, São Paulo, 2008.

INSTITUTO SOCIOAMBIENTAL. Povos indigenas no Brasil. Disponível em: $<$ https://pib.socioambiental.org/pt $>$. Acesso em: 20 fev. 2017.

KAHN, Marina. "Educação indígena" versus educação para índios: sim, a discussão deve continuar. Em Aberto, Brasília, v. 14, n. 63, p. 137-144, 1994.

LÉVI-STRAUSS, Claude. Tristes trópicos. Tradução de Rosa Freire D'Aguiar. 12. ed. São Paulo: Companhia das Letras, 2014.

MARQUI, Amanda Rodrigues. Tornar-se aluno(a) indígena: a etnografia da escola Guarani Mbya na aldeia Nova Jacunda. 2012. 147 p. Dissertação (Mestrado em Antropologia Social) Universidade Federal de São Carlos, São Carlos, 2012.

MARRAS, Stelio. Como não terminar uma tese: pequeno diálogo entre o estudante e seus colegas (after hours). Cadernos de Campo, n. 14-15, São Paulo, p. 353-382,2006.

MELIÀ, Bartolomeu. Educação indígena e alfabetização. 1.ed. São Paulo: Loyola, 1979.

SAHLINS, Marshall. O "pessimismo sentimental" e a experiência etnográfica: por que a cultura não é um "objeto" em via de extinção (parte I). Mana, Rio de Janeiro, v. 3, n. 1, p. 41-73, 1997.

SANTIAGO, Ana Elisa. Entre papeis, pessoas e perspectivas: etnografia da gestão da educação escolar indígena em Altamira - PA. 2014. 135 p. Dissertação (Mestrado em Antropologia Social) Universidade Federal de São Carlos, São Carlos, 2014.

SANTOS, Douglas Ladislau dos. O fenômeno aula entre os Guarani Mbya: as arma (dilhas) da escola. Revista Contemporânea de Educação, Rio de Janeiro, v. 13, n. 26, p. 146-163, jan/abr 2018.

SILVA, Aracy Lopes da (Org.). A questão da educação indígena. 1. ed. São Paulo: Brasiliense; Comissão Pró-Índio, 1981.

TASSINARI, Antonella Maria Imperatriz. Escola indígena: novos horizontes teóricos, novas fronteiras da educação. In: FERREIRA, Mariana Kawall Leal; SILVA, Aracy Lopes da. Antropologia, história e educação: a questão indígena e a escola. São Paulo: Fapesp, 2001, p. 44-70.

TESTA, Adriana Queiroz. Palavra, sentido e memória: educação e escola nas lembranças dos Guarani Mbya. 2007. 213 p. Dissertação (Mestrado em Educação) - Universidade de São Paulo, São Paulo, 2007.

TSUPAL, Nancy Antunes. Educação indígena bilingue, particularmente entre os Karaja e Xavante: alguns aspectos pedagógicos, considerações e sugestões. 1978. 173 p. Dissertação (Mestrado) - Universidade de Brasília, Brasília, 1978.

VALENTINI, Aline de Alcântara. Educação escolar indígena Guarani: a escola estadual indígena Djekupé Amba Arandu (São Paulo - SP) e seus desafios para a construção de uma escola indígena de caráter diferenciado. 2010. 146 p. Dissertação (Mestrado em Educação) - Faculdade de Educação, PUC, São Paulo, 2010. 


\section{Sobre o autor}

Douglas Ladislau dos Santos é sociólogo. Mestre em Educação. Doutorando do Programa de Pós-Graduação em Educação da Faculdade de Educação da Universidade de São Paulo, sob a orientação do Prof. Dr. Elie Ghanem. Pesquisador do Centro Universitário de Investigações em Inovação, Reforma e Mudança Educacional (Ceunir).

Recebido em outubro de 2017.

Aprovado em maio de 2018. 